\title{
Estimation of the carcass composition of yearling bulls of "Asturiana de los Valles" breed from the dissection of a rib joint
}

\author{
M. Oliván *, A. Martínez, P. García, G. Noval, K. Osoro \\ SERIDA, Apdo 13,33300 Villaviciosa, Asturias, Spain
}

Received 19 January 2000; received in revised form 27 June 2000; accepted 27 June 2000

\begin{abstract}
To evaluate different methods of estimating bovine carcass composition, seventy yearling bulls of the "Asturiana de los Valles" beef breed were slaughtered and their carcass composition estimated by a commercial dissection of the right half-carcass and by tissular dissection of the 6th and 10th rib of the left half-carcass. Correlation and regression analyses were used to identify the most accurate predictors of carcass composition. In simple regression, the percentage of lean in the 10th rib was the most accurate predictor $(r=0.88 ; P<0.001)$ of the lean proportion in the carcass and the percentage of fat in the 6 th rib was the best predictor $(r=0.90 ; P<0.001)$ of the carcass fat content. The correlation coefficients for estimating the bone percentage in the carcass from the bone proportion in the ribs (6th and 10th) were low $(r=0.63$ and 0.51 respectively), although significant $(P<0.001)$ and the coefficient improved when the proportion of lean in the ribs was used as predictor $(r=0.78$ and 0.70 for the 6 th and the 10 th rib respectively). In multiple regression, the addition of more regressors of the rib composition and carcass traits, such as carcass hot weight, the carcass fatness score and the weight of the kidney knob and channel fat, led to an improvement $(P<0.05)$ in accuracy for some predictions. The results in general show that the accuracy of the predictions for the carcass composition obtained from dissection of both the 6th and 10th ribs was similar, although the dissection of the 10th rib tended to overestimate the proportion of fat in the carcass. Therefore, considering the carcass quartering method for the extraction of the ribs, it is proposed that dissection of the 6 th rib is more appropriate than dissection of the 10th rib so as not to reduce the carcass value and obtain a good estimate of the carcass composition. (C) 2000 Elsevier Science Ltd. All rights reserved.
\end{abstract}

Keywords: Carcass composition; Lean; Fat; Bone; Prediction; Dissection; Rib

\section{Introduction}

The carcass quality is determined by different characteristics that determine its relative value to the meat industry. The main parameters of carcass quality are lean and fat proportions, lean:bone ratio and saleable meat yield (Fisher, Wood \& Whelehan, 1986; Wood, Fisher \& Whelehan, 1986). These can be measured accurately by full carcass dissection, but this is a time consuming, destructive and expensive process, therefore predictors are often used and equations developed relating such predictor values to the parameter of interest.

Indirect methods for carcass composition assessment can be based on in vivo or carcass measurements. The prediction from live animals is important in evaluating meat animals for marketing or genetic selection purposes

* Corresponding author. Tel.: +34-98-5890066; fax: + 34-98-5891 854.

E-mail address: carmenog@princast.es (M. Oliván). and is based mainly on handling score (Renand \& Fisher, 1997), ultrasound technology (Houghton \& Turlington, 1992) or the diameter of subcutaneous adipose cells (Robelin \& Agabriel, 1986). The main carcass traits used as predictors of the carcass composition in beef carcasses are carcass weight, subcutaneous fat thickness, eye muscle area and dissection of a rib joint (Robelin, Geay \& Beranger, 1974; Robelin \& Geay, 1975a,b; Jonhson \& Baker, 1997).

When performing a dissection of a joint of the carcass, it is important to follow a standardised approach for cutting the samples and separating the tissues. The EU standard method for beef dissection proposes quartering of the carcass behind the 13th rib by a curve cut with the knife held against the bone (Williams \& Bergstrom, 1980). But this method requires cutting one of the joints of highest value in the carcass, which produces a high devaluation of the carcass. Robelin and Geay (1975b) proposed the dissection of the 6th rib, extracted from the carcass by a straight cut, to obtain a good 
estimation of the carcass composition of young males of different breeds (Frisonne, Charolaise, Limousine, Salers). This part of the rib joint is easier to cut because it is located at the point where the carcass is quartered for commercial purposes, and thus the devaluation of the carcass is less.

The aim of this work was to compare the accuracy of the prediction of the carcass composition of yearling bulls of "Asturiana de los Valles" from dissection of two different rib joints: the 6th rib (obtained by a straight sawcut at the point where the carcass is quartered for commercial uses) and the 10th rib (extracted by a curve cut from the middle of the rib joint).

\section{Materials and methods}

\subsection{Animals and management}

Seventy yearling bulls from the "Asturiana de los Valles" breed were used, 35 in 1997 and 35 in 1998. The "Asturiana de los Valles" is a beef breed of North Spain adapted to extensive production systems and with a high percentage of double-muscled animals.

The calves were managed with their mothers from birth (winter) to weaning (October). After weaning the male calves were fed with concentrated $(84 \%$ barley meal, $10 \%$ soya meal, $3 \%$ fat, $3 \%$ minerals, vitamins and oligoelements) and barley straw ad libitum in the housing facilities of the Institute. Animals were slaughtered on reaching a mean live weight around $500 \mathrm{~kg}$. Slaughtering was performed in a commercial abattoir according to routine procedure in 11 batches corresponding to 6 days of slaughter in 1997 and 5 days in 1998.

\subsection{Measurements}

The yearling bulls were weighed twice (the day of slaughter and the day before) to get the final live weight. After slaughtering and dressing, the hot carcass weight was recorded and the carcasses were chilled at $3^{\circ} \mathrm{C}$ for $24 \mathrm{~h}$ before measurements were made.

The day following the slaughter, the carcasses were classified for conformation and fat cover by a trained and experienced evaluator, according to the EUROP system, using a scale from 1 to 15 for conformation, with 15 being the best conformation, and a scale from 1 to 5 for fat cover, with 5 being the thickest fat cover. The kidney knob and channel fat was removed and weighed.

The left half carcass was quartered between the 5th and 6th thoracic vertebrae with a circular saw, as used commercially, and two ribs were extracted as follows:

- The 6th rib was extracted by a straight cut perpendicular to the vertebral axis, from the middle of each intercostal space to the vertebrae, cutting the length of the bone at the limit of the serrato dorsal muscle (Robelin \& Geay, 1975b).

- The 10th rib was extracted by a curve cut with a knife held against the bone (Williams \& Bergström, 1980), cutting the length of the bone at the level of the diaphragm with a saw.

The total weight of each rib was recorded at the laboratory. The longissimus thoracis muscle was separated and weighed and the rest of the rib was frozen at $-20^{\circ} \mathrm{C}$.

Two days after slaughter, the right half of each carcass was dissected according to commercial practice; this involved a close trimming and deboning of the lean (except the ribs, that maintained the bone). The total dissected weights of lean, bone and fat were recorded. The total weight of the rib joint was recorded as lean. Other tissues (blood vessels, ligaments, tendons) were recorded as bone.

The 6th and 10th ribs were stored at $-20^{\circ} \mathrm{C}$ until dissection. Then, they were thawed overnight at $4{ }^{\circ} \mathrm{C}$ and dissected into lean, fat (subcutaneous and intermuscular), bone and other tissues (blood vessels, ligaments, tendons). Other tissues were recorded as bone.

\subsection{Statistical analysis}

Regression analysis was used to relate carcass composition traits, obtained from commercial dissection of the right half-carcass, with the predictors obtained from dissection of the 6th and 10th ribs of the left half-carcass. The dependent variables, reflecting carcass composition, were $\%$ lean (lean weight/carcass weight), $\%$ fat (fat weight/carcass weight), $\%$ bone (bone weight/ carcass weight) and lean to bone ratio (lean weight/bone weight). Independent variables were the measurements of the composition of the 6th and 10th ribs ( \% lean, \% fat, $\%$ bone, lean:bone ratio), and other carcass traits: carcass weight, fatness score and kidney knob and channel fat weight. The regression analyses were performed with the SPSS 6.1. (1994) personal computer programme and the independent variables were selected by the stepwise method. Relationships between variables were assessed by Pearson correlation coefficients and the accuracy of the predictions were described by the residual standard deviation of the regressions.

Means, standard deviations and coefficients of variation of the carcass composition traits are reported in Table 1. The sample of 70 animals was relatively homogeneous in the proportion of lean, bone and fat in the carcass (the maximum standard deviation was 3.34 for the $\%$ lean). The largest variability was observed in fat content, with a coefficient of variation of 32.83 for the fat weight and 35.39 for fat percentage. The data indicate that the carcasses were lean (from 2 to $12 \%$ fat) which are characteristics of the "Asturiana de los Valles" breed. This is a beef breed with a high percentage 
Table 1

Half-carcass dissection traits

\begin{tabular}{lrrrr}
\hline & Mean & Range & Standard deviation & Coefficient of variation \\
\hline Liveweight $(\mathrm{kg})$ & 509.24 & $463-622$ & 25.08 & 4.93 \\
Carcass weight $(\mathrm{kg})$ & 324.37 & $288-406$ & 21.63 & 6.67 \\
Lean weight $(\mathrm{kg})$ & 261.65 & $216-333$ & 24.64 & 9.42 \\
Bone weight $(\mathrm{kg})$ & 42.32 & $34-55$ & 4.28 & 10.11 \\
Fat weight $(\mathrm{kg})$ & 20.41 & $7-36$ & 6.70 & 32.83 \\
\% Lean & 80.55 & $74-86$ & 3.34 & 4.15 \\
\% Bone & 13.09 & $10-17$ & 1.47 & 11.21 \\
\% Fat & 6.36 & $2-12$ & 2.25 & 35.39 \\
Lean to bone ratio & 6.25 & $4-8$ & 0.92 & 14.75 \\
\hline
\end{tabular}

of double-muscled individuals and produces carcasses of good conformation and low fat cover.

\section{Results and discussion}

The data obtained from dissection of both the 6th or 10th ribs gave lower proportions of lean and higher of fat and bone than obtained from dissection of the halfcarcass, shown in Table 1 (lean: $76.0 \%$ in the 6th rib, $73.1 \%$ in the 10 th rib, $80.6 \%$ in half-carcass; fat: $8.5 \%$ in the 6th rib, $10.2 \%$ in the 10 th rib, $6.4 \%$ in the halfcarcass; bone: $15.6 \%$ in the 6 th rib, $16.7 \%$ in the 10 th rib, $13.1 \%$ in half-carcass). This could be due to the commercial dissection of the right half-carcass, that would produce a slight overestimation of the lean content since some lean joints contain small amounts of intermuscular fat and the rib joint was weighed with bone, although it was recorded as lean. However, it is clear that the composition of the 6th rib was more similar to that of the carcass for all the composition traits, with a higher percentage of lean and lower percentage of fat and bone than the 10th rib. (Figs. 1-3).

The variables that contributed significantly to the prediction of the carcass composition traits in a simple regression are shown in Table 2 . There was a significant correlation $(P<0.001)$ between the proportion in the half-carcass of lean $(\mathrm{CL})$, fat $(\mathrm{CF})$, bone $(\mathrm{CB})$ and lean:bone ratio (L:B) and its proportion in each rib (L6, F6, B6, L6:B6 in the 6th rib; L10, F10, B10, L10:B10 in the 10th rib). The highest correlations were between $\mathrm{CF}$ and the fat proportion (F6 and F10) in the rib joints $(r=0.90$ and 0.87 respectively; $P<0.001)$ and between $\mathrm{CL}$ and the lean proportion (L6 and L10) in the ribs $(r=0.87$ and 0.88 respectively; $P<0.001)$. These coefficients are higher than obtained by Vallejo, Gutierrez, Gima et al., (1992) when comparing the tissular composition of the carcass with that of a rib joint extracted at the 11th and 12th rib ( $r=0.58$ for fat, $r=0.62$ for lean) in yearling bulls of the "Asturiana de los Valles" breed. However, the coefficients of regression between the bone proportion in the carcass $(\mathrm{CB})$ and that of the

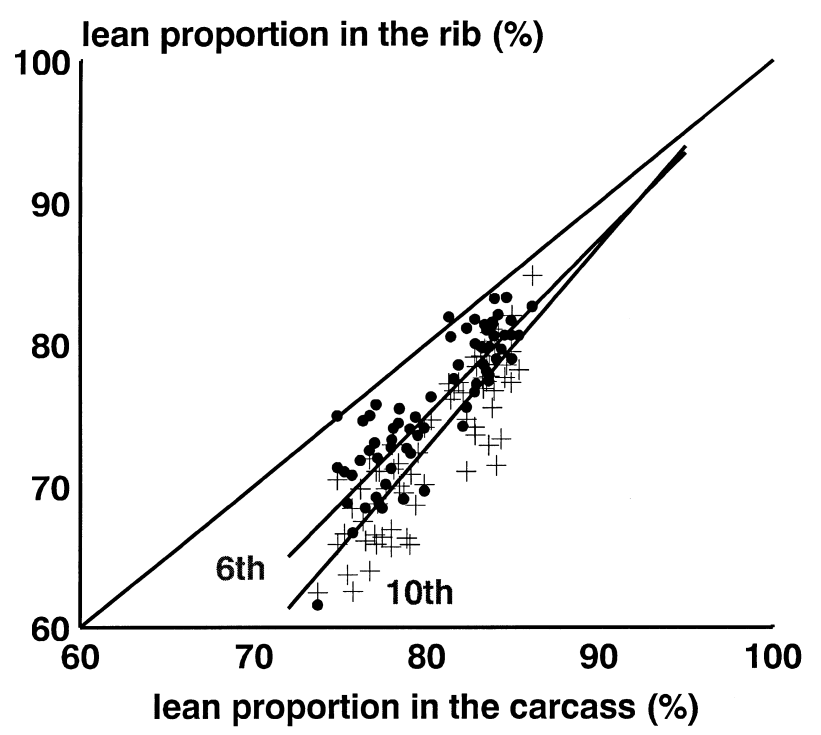

Fig. 1. Relationship between the lean proportion in the half-carcass and the lean proportion in the ribs $(\bullet 6 \mathrm{th},+10$ th $)$.

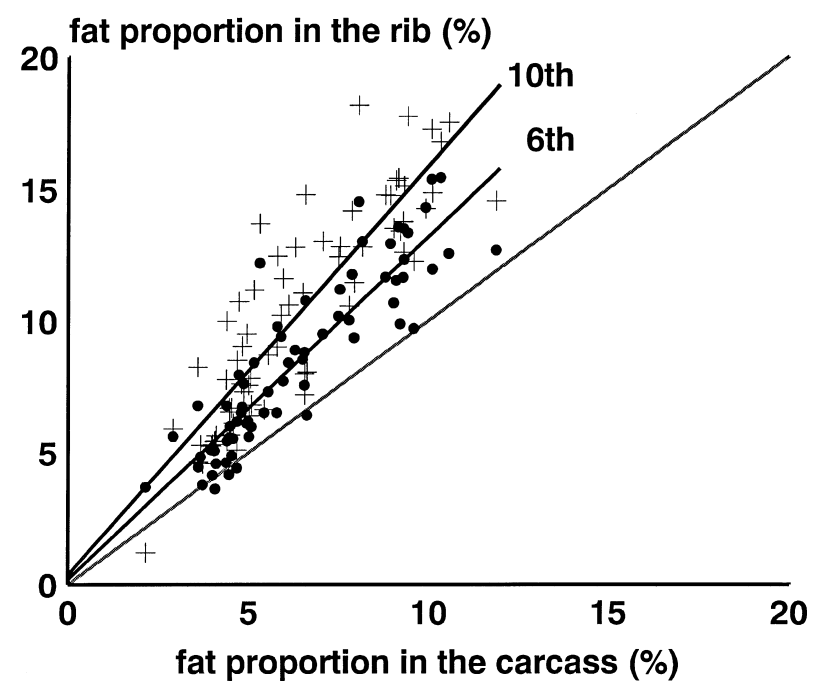

Fig. 2. Relationship between the fat proportion in the half-carcass and the fat proportion in the ribs $(\bullet 6$ th,+10 th $)$. 


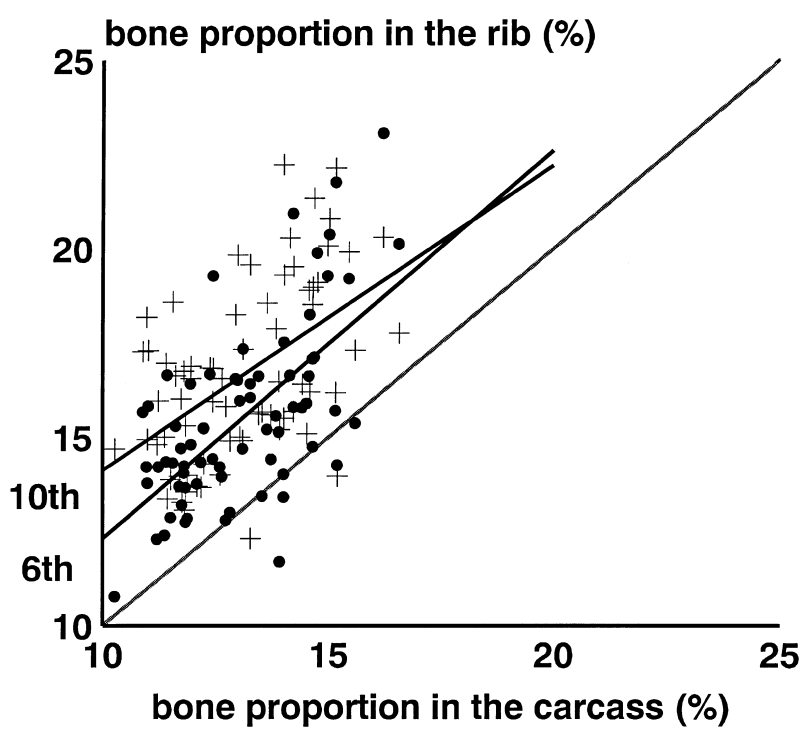

Fig. 3. Relationship between the bone proportion in the half-carcass and the bone proportion in the ribs $(\bullet 6$ th,+10 th $)$.

6th or 10th ribs (B6 and B10) were lower $(r=0.63$ and 0.51 respectively), although significants $(p<0.001)$. These results are similar to the results obtained by Vallejo, Gutierrez, Alonso et al., (1992) and Vallejo, Gutierrez, Cima et al., (1992), who obtained low correlations when estimating the bone proportion in the bovine carcasses from the bone proportion in a rib joint. There was a significant improvement $(P<0.05)$ in the estimation of the bone proportion in the carcass $(\mathrm{CB})$ when using as predictors the lean proportion (L6 and L10) in the ribs $(r=0.78$ and 0.70 respectively; $P<0.001$ ). These variables (L6 and L10) also gave the best prediction of the lean:bone ratio $(\mathrm{L}: \mathrm{B})$ in the carcass $(r=0.83$ and 0.77 respectively; $P<0.001)$.
When calculating multiple regressions (Table 3) that included all the rib composition traits (\%lean $+\%$ fat $+\%$ bone + lean:bone) and some carcass traits, like carcass weight $(\mathrm{CW})$, fatness score (F) and the kidney knob and channel fat weight (KKCF), there was a significant $(P<0.05)$ improvement of the prediction of the lean proportion in the carcass. The 6 th rib traits, lean and fat proportion $(\mathrm{L} 6+\mathrm{F} 6)$ or fat and bone proportion $(\mathrm{F} 6+\mathrm{B} 6)$, were the most accurate contributors to the prediction of the lean proportion in the carcass $(r=0.91$, r.s.d. $=1.37, P<0.001)$ and explained $84 \%$ of the variance of the carcass lean content $\left(R^{2}=0.84\right)$, better than the 10th rib traits, lean and fat proportion $(\mathrm{L} 10+\mathrm{F} 10)$, which explained only $79 \% \quad(r=0.89$, r.s.d. $=1.52$, $P<0.001$ ). The use of more regressors (different rib components or carcass traits) did not lead to an increase in the accuracy of estimation of the lean proportion.

In estimating the fat proportion of the carcass $(\mathrm{CF})$, the best prediction was obtained from the composition of the 6th rib, using as single predictor the fat proportion in the rib $(r=0.90$, r.s.d. $=1.01, P<0.001$, Table 2$)$. The addition of more regressors did not give any significant improvement.

When estimating the bone proportion of the carcass (CB), the best prediction was also obtained from the 6th rib composition, especially from the proportion of lean, explaining $61 \%$ of the variance $(r=0.78, P<0.001$, Table 2). The use of two predictors (proportion of bone in the ribs plus $\mathrm{CW}$ or $\mathrm{F}$ ) gave significant regressions, but did not improve the prediction $(r=0.68$ and 0.72 for $\mathrm{B} 6+\mathrm{CW}$ and $\mathrm{B} 6+\mathrm{F}, r=0.58$ and 0.65 for $\mathrm{B} 10+\mathrm{CW}$ and $\mathrm{B} 10+\mathrm{F}$, respectively, Table 3 ).

The best prediction of the lean:bone ratio $(\mathrm{L}: \mathrm{B})$ in the carcass was again obtained from the proportion of lean in the 6th rib $(r=0.83$, r.s.d. $=0.52$, Table 2$)$ and the use of more predictors did not improve the prediction.

Table 2

Correlation coefficients and residual standard deviations of simple regressions between the half-carcass commercial dissection traits and the composition of the 6th and 10th rib

\begin{tabular}{|c|c|c|c|c|c|c|c|c|}
\hline \multirow[b]{3}{*}{ Predictors $^{\mathrm{a}}$} & \multicolumn{8}{|c|}{ Carcass dissection } \\
\hline & \multicolumn{2}{|c|}{ \% Lean (CL) } & \multicolumn{2}{|c|}{ \% Fat (CF) } & \multicolumn{2}{|c|}{ \% Bone (CB) } & \multicolumn{2}{|c|}{ Lean:bone (L:B) } \\
\hline & $r^{\mathrm{b}}$ & r.s.d & $r^{\mathrm{b}}$ & r.s.d. & $\mathbf{r}^{\mathrm{b}}$ & r.s.d. & $r^{\mathrm{b}}$ & r.s.d. \\
\hline \multicolumn{9}{|l|}{ 6th rib traits: } \\
\hline $\mathrm{L} 6^{* * *}$ & $0.87^{* * *}$ & 1.66 & & & $0.78^{* * *}$ & 0.92 & $0.83^{* * *}$ & 0.52 \\
\hline $\mathrm{F} 6^{* * *}$ & & & $0.90^{* * *}$ & 1.01 & & & & \\
\hline $\mathrm{B} 6^{* * *}$ & & & & & $0.63^{* * *}$ & 1.15 & & \\
\hline $\mathrm{L} 6: \mathrm{B} 6^{* * *}$ & & & & & & & $0.70^{* * *}$ & 0.67 \\
\hline \multicolumn{9}{|l|}{ 10th rib traits: } \\
\hline $\mathrm{L} 10^{* * *}$ & $0.88^{* * *}$ & 1.63 & & & $0.70^{* * *}$ & 1.06 & $0.77^{* * *}$ & 0.59 \\
\hline $\mathrm{F} 10^{* * *}$ & & & $0.87^{* * *}$ & 1.10 & & & & \\
\hline $\mathrm{B} 10^{* * *}$ & & & & & $0.51^{* * *}$ & 1.27 & & \\
\hline $\mathrm{L} 10: \mathrm{B} 10^{* * *}$ & & & & & & & $0.63^{* * *}$ & 0.72 \\
\hline
\end{tabular}

a Variables and significance (*: $P<0.05, * *: P<0.01, * * *: P<0.001)$.

b Correlation coefficient and significance of regression (*: $P<0.05$, **: $P<0.01$, ***: $P<0.001$ ). 
Table 3

Correlation coefficients and residual standard deviations in multiple regressions between the half-carcass commercial dissection traits and the composition of the 6th and 10th rib

\begin{tabular}{|c|c|c|c|c|c|c|c|c|}
\hline \multirow[b]{3}{*}{ Predictors $^{\mathrm{a}}$} & \multicolumn{8}{|c|}{ Carcass dissection } \\
\hline & \multicolumn{2}{|c|}{$\%$ Lean $(\mathrm{CL})$} & \multicolumn{2}{|c|}{$\%$ Fat $(\mathrm{CF})$} & \multicolumn{2}{|c|}{$\%$ Bone $(\mathrm{CB})$} & \multicolumn{2}{|c|}{ Lean:bone (L:B) } \\
\hline & $r^{\mathrm{b}}$ & r.s.d. & $\mathrm{r}^{\mathrm{b}}$ & r.s.d. & $r^{\mathrm{b}}$ & r.s.d. & $r^{\mathrm{b}}$ & r.s.d. \\
\hline \multicolumn{9}{|l|}{ 6th rib traits: } \\
\hline $\mathrm{L} 6^{* *}+\mathrm{F} 6^{* * *}$ & $0.91^{* * *}$ & 1.37 & & & & & & \\
\hline $\mathrm{F} 6^{* * *}+\mathrm{B} 6^{* * *}$ & $0.91^{* * *}$ & 1.37 & & & & & & \\
\hline $\mathrm{L} 6^{* * *}+\mathrm{F}^{* \mathrm{c}}$ & $0.88^{* * *}$ & 1.61 & & & & & & \\
\hline $\mathrm{B}^{* * *}+\mathrm{CW}^{* *{ }_{\mathrm{c}}}$ & & & & & $0.68^{* * *}$ & 1.08 & & \\
\hline $\mathrm{B} 6^{* * *}+\mathrm{F}^{* * *}$ & & & & & $0.72^{* * *}$ & 1.02 & & \\
\hline $\mathrm{L} 6: \mathrm{B}^{* * *}+\mathrm{CW}^{*}$ & & & & & & & $0.73^{* * *}$ & 0.64 \\
\hline $\mathrm{L} 6: \mathrm{B}^{* * *}+\mathrm{F}^{* * *}$ & & & & & & & $0.77^{* * *}$ & 0.59 \\
\hline \multicolumn{9}{|l|}{ 10th rib traits: } \\
\hline $\mathrm{L} 10^{* *}+\mathrm{F} 10^{* *}$ & $0.89^{* * *}$ & 1.52 & & & & & & \\
\hline $\mathrm{L} 10^{* * *}+\mathrm{KKCF}^{* \mathrm{c}}$ & $0.88^{* * *}$ & 1.58 & & & & & & \\
\hline $\mathrm{B} 10^{* * *}+\mathrm{CW}^{* *}$ & & & & & $0.58^{* * *}$ & 1.21 & & \\
\hline $\mathrm{B} 10^{*}+\mathrm{F}^{* * * *}$ & & & & & $0.65^{* * *}$ & 1.13 & & \\
\hline $\mathrm{L} 10: \mathrm{B} 10^{* *}+\mathrm{F}^{* * *}$ & & & & & & & $0.72^{* * *}$ & 0.65 \\
\hline
\end{tabular}

a Variables and significance (*: $P<0.05, * *: P<0.01, * * *: P<0.001)$.

b Correlation coefficient and significance of regression (*: $P<0.05$, **: $P<0.01$, ***: $P<0.001$ ).

${ }^{c}$ CW: carcass weight, F: fatness; KKCF: kidney knob and channel fat.

These results show in general a better prediction of carcass composition from dissection of the 6th rib than the 10th. This agrees with results obtained by Robelin and Geay (1975a,b), when calculating the carcass composition of young bulls of different breeds (Frisonne, Charolaise, Limousine, Salers) from the tissular composition of the 6th (Robelin \& Geay, 1975a) or the 11th rib (Robelin \& Geay, 1975b). These authors found that carcass weight plus the proportion of lean and fat in the 6th rib (Robelin \& Geay, 1975a) estimated accurately the weight of fat and lean in the carcass (r.s.d. 3.36 and 3.90 for fat and lean respectively), although dissection of the 11th rib gave also good estimation of carcass composition, when used together with other predictors such as carcass weight, kidney knob and channel fat weight and the compacity of the hindlimb (Robelin \& Geay, 1975b). However, they proposed the use of the 6th rib as the easier and more economic method.

Renand and Fisher (1997) also used dissection of the 6th rib as a predictor of carcass composition when comparing different methods of estimating the carcass fat content of young bulls. They studied the accuracy of different in vivo measurements such as handling scores, fat thickness measured by scanning, ultrasound velocity through the back and hind limb and the diameter of subcutaneous adipose cells, by reference to the carcass composition estimated from the dissection of the 6th rib. They obtained a relatively high correlation $(0.71)$ between carcass fat thickness measured on the 6th rib and carcass fat content, estimated from the prediction equation developed by Robelin and Geay (1975b).
The results of the present study gave lower correlation coefficients than the work of Robelin and Geay (1975b), who calculated regression equations to estimate carcass composition from the composition of the 6th rib joint and some carcass traits. They obtained values of $R^{2}=$ 0.942 for fat, $R^{2}=0.996$ for lean and $R^{2}=0.902$ for bone. This can be explained in part, because in the present work the animals were relatively homogeneous, in that they belong to the same breed and were slaughtered at a similar live weight (around $500 \mathrm{~kg}$ ) giving carcass weights from 288 to $406 \mathrm{~kg}$. However, the prediction equations of Robelin and Geay (1975b) were calculated from an heterogeneous sample of 80 animals of different breeds with carcass weights from 144 to $452 \mathrm{~kg}$ and carcass compositions of higher heterogeneity (fat weight from 14 to $61 \mathrm{~kg}$, muscle weight from 98 to $352 \mathrm{~kg}$ and bone weight from 25 to $52 \mathrm{~kg}$ ) than the animals used in this study (Table 1).

In the literature, carcass composition was less well predicted by different carcass traits and in vivo measurements than in the present work (Laville, Martin \& Bastien, 1996; Renand \& Fisher, 1997). The correlations between morphological traits as single predictors of carcass composition obtained by Laville et al., (1996) were moderate or low $(r=0.69$ for muscle weight, $r=0.48$ for fat weight). Only when using several carcass traits as predictors did they obtain a high fit for the prediction of muscle weight $\left(R^{2}=0.98\right)$. For a sample of 136 young Charolais bulls Renand and Fisher (1997) found that the adipose cell diameter and the speed of ultrasound through the back explained $42 \%$ of the 
variance in fat content, a lower percentage than that obtained in the present study, where the fat proportion in the 6 th rib explained $80 \%$ of the variance in the fat content of the carcass.

For the sample of young bulls in this study, the accuracy of the predictions obtained from the composition of both 6th and 10th ribs was similar, with low values of the residual standard deviation $(<1.66 \%)$. However, dissection of the 10th rib tended to overestimate the proportion of fat as the fat content of the carcass increased (Fig. 2). This could be due to the type of cut of the rib, that included the whole bone, a place where the fat depots increase as the fatness score of the carcass increases. This indicates clearly that dissection of the 6th rib is more appropriate to obtain the best estimation of the carcass composition, especially for the fat content, one of the most important carcass traits from the commercial point of view.

The results of this study support the conclusion that the composition of the 6th rib allows accurate estimation of the carcass composition, giving better prediction equations that the composition of the 10th rib and being the easier and more economic method.

\section{References}

Fisher, A. V., Wood, J. D., \& Whelehan, O. P. (1986). The effects of a combined androgenic-oestrogenic anabolic agent in steers and bulls. 1 . Growth and carcass composition. Animal Production, 42, 203-211.

Houghton, P. L., \& Turlington, L. M. (1992). Application of ultrasound for feeding and finishing animals: a review. Journal of Animal Science, 70, 930-941.

Johnson, E. R., \& Baker, D. A. (1997). Use of linear measurements of m. longissimus to predict the muscle content of beef carcasses. Meat Science, 45(3), 321-327.

Laville, E., Martin, V., \& Bastien, O. (1996). Prediction of composition traits of young charolais bull carcasses using a morphometric method. Meat Science, 44(1-2), 93-104.

Renand, G., \& Fisher, A. V. (1997). Comparison of methods for estimating carcass fat content of young Charolais bulls in performance testing station. Livestock Production Science, 51, 205-213.

Robelin, J., \& Agabriel, J. (1986). Estimation de l'état d'engraissement des bovins vivants à partir de la taille des cellules adipeuses. Bull. Tech. C.R.Z.V. Theix, I.N.R.A, 66, 37-41.

Robelin, J., \& Geay, Y. (1975a). Estimation de la composition des carcasses de jeunes bovins a partir de la composition d'un morceau monocostal prélevé au niveau de la 11e côte. Annales of Zootechnie, 24(3), 391-402.

Robelin, J., \& Geay, Y. (1975b). Estimation de la composition de la carcasse des taurillons a partir de la composition de la bème côte. Bull. Techn. C.R.Z.V. Theix, I.N.R.A, 22, 41-44.

Robelin, J., Geay, Y., \& Beranger, C. (1974). Estimation de la composition des carcasses des jeunes bovins mâles à partir de la composition de la 11 ème côte. Bull. Techn.C.R.Z.V. Theix, I.N.R.A, 17, $15-18$.

SPSS 6.1 for Windows (1994) Chicago, USA: SPSS Inc.

Vallejo, M., Gutiérrez, J. P., Alonso, L., Cañón, J., Revuelta, J. R., Goyache, F., \& Cima, M. (1992a). Características de las canales de las razas bovinas asturianas. II. (Valoración cuantitativa y predicción de la composición tisular de canales en la raza "Asturiana de la Montaña"). Archivos de Zootecnia, 41, 645-656.

Vallejo, M., Gutiérrez, J. P., Cima, M., Cañón, J., Alonso, L., Revuelta, J. R., \& Goyache, F. (1992b). Características de las canales de las razas bovinas asturianas. III. (Valoración cuantitativa y predicción de la composición tisular de canales en la raza "Asturiana de los Valles"). Archivos de Zootecnia, 42, 29-40.

Williams, D.R. \& Bergström, P.L. (1980). Auatomical jointing, tissue separation \& weight recording. E.E.C. standard method for beef. Commission of the European Communities. EUR 6878 EN.

Wood, J. D., Fisher, A. V., \& Whelehan, O. P. (1986). The effects of a combined androgenic-oestrogenic anabolic agent in steers and bulls. 2. Muscle weight distribution, partition of body fat and carcass value. Animal Production, 42, 213-222. 